\title{
Overland movement in African clawed frogs (Xenopus laevis): a systematic review
}

\author{
John Measey ${ }^{\text {Corresp. } 1}$ \\ 1 DST-NRF Centre of Excellence for Invasion Biology, Department of Botany \& Zoology, Stellenbosch University \\ Corresponding Author: John Measey \\ Email address: john@measey.com
}

African clawed frogs (Xenopus laevis) are often referred to as 'purely aquatic' but there are many publications which suggest extensive overland movements. Previous reviews which considered the topic have not answered the following questions: a) is there evidence for overland dispersal in native and invasive ranges? b) what is the range of distances moved overland? c) when does overland movement occur? and d) is there evidence of breeding migratory behaviour? A systematic review was chosen to synthesise and critically analyse all literature on the overland movement in Xenopus laevis. Database searches resulted in 57 documents which revealed a paucity of empirical studies, with 28 containing no data, and 19 having anecdotal content. Overwhelming evidence shows that both native and invasive populations of $X$. laevis move overland, with well documented examples for several other members of the genus $(X$. borealis, $X$. gilli, $X$. muelleri, $X$. fraseri and $X$. tropicalis). Reports of distances moved overland were from $40 \mathrm{~m}$ to $2 \mathrm{~km}$, with no apparent difference between native and invasive ranges. Overland movements are not confined to wet seasons or conditions, but the literature suggests that moving overland does not occur in the middle of the day. Migrations to temporary water-bodies for breeding have been suggested, but without any corroborating data. 
1 Overland movement in African clawed frogs (Xenopus laevis): a systematic review

2

3 John Measey ${ }^{1}$

$4 \quad{ }^{1}$ Centre for Invasion Biology, Department of Botany \& Zoology, Stellenbosch University, Private Bag X1,

5 Matieland 7602, Stellenbosch, South Africa

6

7 Summary

8 African clawed frogs (Xenopus laevis) are often referred to as 'purely aquatic' but there are many

9 publications which suggest extensive overland movements. Previous reviews which considered the topic

10 have not answered the following questions: a) is there evidence for overland dispersal in native and

11 invasive ranges? b) what is the range of distances moved overland? c) when does overland movement

12 occur? and d) is there evidence of breeding migratory behaviour? A systematic review was chosen to synthesise and critically analyse all literature on the overland movement in Xenopus laevis. Database searches resulted in 57 documents which revealed a paucity of empirical studies, with 28 containing no data, and 19 having anecdotal content. Overwhelming evidence shows that both native and invasive populations of $X$. laevis move overland, with well documented examples for several other members of the genus (X. borealis, X. gilli, X. muelleri, X. fraseri and X. tropicalis). Reports of distances moved overland were from $40 \mathrm{~m}$ to $2 \mathrm{~km}$, with no apparent difference between native and invasive ranges. Overland movements are not confined to wet seasons or conditions, but the literature suggests that moving overland does not occur in the middle of the day. Migrations to temporary water-bodies for breeding have been suggested, but without any corroborating data. 


\section{Introduction}

Dispersal is a key trait in the life-history of any organism influencing the distribution, community structure and abundance of populations (Clobert et al 2009). In anthropogenically disturbed environments, dispersal may be interrupted or facilitated by novel landscape features that may hinder the conservation of threatened species or facilitate the spread of invasive species (Carr \& Fahrig 2001; Brown et al 2006). For invasive species, dispersal is one of the main variables which determines the success of establishment, as well as the rate of spread (Wilson et al 2009). In fact, dispersal affects some aspects of all ecological, evolutionary and conservation problems. Amphibians are model organisms for studies in dispersal as they are generally thought to have low dispersal abilities which brings about strong phylogeographical structuring (e.g. Avise 2000).

Despite their reputation for strong site fidelity, amphibians have been shown to have considerable dispersal abilities. Smith \& Green (2005) reviewed evidence for maximum dispersal in amphibians and concluded that although most individual anurans move short distances $(<1 \mathrm{~km})$, small numbers of individuals could be expected to move much further $(>10 \mathrm{~km})$. Moreover, these dispersal events may well be informed by a multisensory orientation system that enables individuals to locate water-bodies in which to complete their complex life-histories (Sinsch 2006). For most amphibians, this involves laying eggs into water where larvae grow and metamorphose to emerge onto land. But for frogs in the genus Xenopus, adults inhabit the same water as their eggs and larvae, prompting many workers to refer to them as 'completely' or 'purely' aquatic (e.g. Elepfandt et al. 2000).

The African clawed frog, Xenopus laevis, is one of four model vertebrate species (Travis 2006), and as such has been distributed to laboratories globally (van Sittert \& Measey 2016), as well becoming very popular in the pet trade (Measey in press). This has resulted in invasive populations on four continents (Measey et al. 2012) and the suggestion that climate-change may increase invasion success in Europe (Ihlow et al. 2016). Surprisingly, the ecology of $X$. laevis is better studied in invasive populations than in their native range, and this lack of ecological data from the native range is problematic as it stymies interpretation of invasive studies. Data on overland movement is particularly important for this principally aquatic amphibian, as it provides insights into dispersal and thus invasion potential.

There is no doubt that Xenopus laevis, like other species in the genus Xenopus and the family Pipidae, are secondarily aquatic (Gans \& Parsons 1966; Trueb 1996), spending the majority of their active time 
57 within water-bodies. They have a number of morphological and anatomical adaptations to an aquatic

58 lifestyle including an extensive lateral line system in adults (Elepfandt 1996), aquatic olfactory receptors

59 (Freitag et al. 1995), type I ilio-sacral articulation for more efficient swimming locomotion (Emerson 1979), aquatic auditory apparatus (Elepfandt et al. 2000) and suction feeding (Carreño \& Nishikawa 2010). However, referring to the species as 'purely aquatic' appears to exclude the possibility of individuals leaving a water-body and travelling overland. It is noteworthy therefore that $X$. laevis retains many traits which have terrestrial functionality, including the auditory apparatus (Katbamna et al. 2006; Mason et al. 2009), the olfactory apparatus (Freitag et al. 1995), and terrestrial jumping and feeding (Measey 1998b). This indicates that terrestrial activities in X. laevis are sufficiently important for these animals to have retained terrestrial functions in addition to aquatic specialisations. Although an alternative explanation is that this could be phylogenetic inertia as their ancestors were terrestrial.

Existing literature on overland movement in Xenopus laevis dates back to anecdotal observations at the beginning of the twentieth century (Hewitt \& Power 1913). However, such records do not appear to agree on whether movements are migrations (to and fro movements of animals between sites; Hey 1949) or animals moving out of drying ponds en masse (Loveridge 1953). On the other hand, there appears to be a paucity of direct evidence, with some authors using inferential evidence of overland movement between isolated ponds. Therefore, I conducted a systematic review (see Moher et al. 2009) using an a priori search strategy and synthesis of all literature on overland movements in African clawed frogs (Xenopus laevis) in order to answer the following questions: 1) What is the evidence in the literature for overland dispersal in native and invasive ranges? 2) What distances are moved overland? 3) When it occurs, is there evidence that overland movement is seasonal or associated with rain or drying habitats? 4) Is there evidence of overland movement being migratory with respect to breeding?

Materials \& Methods

The African clawed frog, Xenopus laevis, has undergone significant taxonomic revision following a comprehensive molecular study by Furman et al. (2015). The results of this revision mean that what was previously known as X. I. laevis by a number of authors (e.g. Kobel et al. 1996; Poynton 1964) is now known as $X$. laevis with all other subspecies being recognised as full species, as well as some newly described species (e.g. Evans et al. 2015). The full range of $X$. laevis is now known to cover much of 
southern Africa: South Africa, Lesotho, Swaziland, Namibia, parts of Botswana, Zimbabwe, parts of Mozambique and extending north into Malawi. While $X$. laevis was the focus of this review, publications that mentioned other species were included and form an integral part of the citation matrix.

\section{Literature review}

A literature search was conducted in Web of Science using the scientific name and derivatives of all common names for Xenopus laevis ("clawed frog", "clawed toad" and "platanna") AND (the Boolean search term to stipulate that the record should contain this AND the next term) four terms related to movement overland ("overland", "terrestrial", "migration" and "dispersal"). This produced a total of 16 search terms of each pair with 988 results (Table S1). These were then searched for papers in which information on overland movement in $X$. laevis was mentioned, resulting in a total of nine unique papers. An additional search for the words "Xenopus overland" (appearing anywhere within a document, and for all years) was made in Google Scholar. Google Scholar has an advantage over other literature databases in that the search term may occur anywhere in the text, instead of just in the title, abstract or keywords. This produced 323 results. Each result was inspected to determine whether or not it contained information on the subject matter. Articles that had no relevance (e.g. author was called Overland or subject was not a pipid) were excluded. The remaining articles $(n=41)$ included all nine from the Web of Science search. Google Scholar results were scrutinised for mention of Xenopus moving overland. Publications where the subjects Xenopus and movement overland were disassociated were removed $(n=5)$. If no evidence was provided but a citation was given, the paper was retained and any citation accessed. Articles that had been cited as giving evidence that Xenopus move overland were retained whether or not they actually contained any pertinent information. Citations provided 16 more documents. Lastly, expert knowledge was used to access a further five documents that did not appear in Google Scholar or in citations. This gave a total of 57 documents (Appendix 1). This collection was biased for literature that had electronic full texts that could be crawled by Google Scholar. The additional documents added through citations and by expert knowledge only partially alleviated this bias. Each document was read critically for the information that it contained on Xenopus moving overland, the species concerned, and with special reference to answering the four study questions. Figure 1 shows a flow diagram for the systematic review following Prisma guidelines (Moher et al. 2009).

\section{Network visualisation}


120 A network visualisation was constructed using Gephi (v 0.8.2) with the aim of showing how citations

121 follow different data types. Literature in the final dataset was classified into five data types: anecdotal

122 (observational reports of frogs moving in terrestrial habitats: $n=19$ ), distributional (occurrence of frogs in

123 water bodies separated by terrestrial habitats from potential source populations: $n=4$ ), mark-recapture

124 (tagged animals located in water bodies separated by terrestrial habitats from those where they had

125 been marked, including a telemetric study: $n=4)$, reviews $(n=4)$ and publications without any relevant

126 data, but that typically cited other papers $(n=28)$. Anecdotal and distributional papers did not always

127 refer to $X$. laevis, despite citations to the contrary. This was in part because of taxonomic adjustments

128 that have only been resolved recently (see above) and partly because citations often referred to

129 overland movements in Xenopus, without specifying the species. Lastly, documents were classified

130 according to whether they were reporting on invasive $(n=16)$ or indigenous $(n=40)$ populations. The

131 network visualisation discriminates between citing and cited publications.

132

133

134

Results \& Discussion

135

Evidence for overland dispersal

136 There is overwhelming support in the literature that Xenopus laevis moves overland from 18 papers in

137 both native (8 papers) and invasive (10 papers) ranges. Most information comes from anecdotal

138 observations (12 papers), where observers directly witnessed animals moving overland. Some reports (4

139 papers) relate to distributional evidence that $X$. laevis had reached isolated ponds, and must have

140 moved overland in order to do so. Although other explanations are possible (e.g. people or would-be

141 predators deliberately or inadvertently moving adults, tadpoles or eggs), in the light of the support from

142 direct observations, it seems more reasonable to accept that these distributional inferences do relate to

143 overland movements. Similarly, mark-recapture studies (3 papers) assume no other agent of overland

144 dispersal is involved. In all three cases this appears more reasonable as time between captures is

145 constrained to periods without water directly linking the sites, although see comments below on

146 Measey \& Tinsley (1998). The telemetric study (Eggert \& Fouquet 2006) was able to follow animals out

147 of ponds and observe them moving overland. Additional reports that refer to other species are covered

148 below.

149

150 Most observational studies report the simultaneous movement of multiple individuals, often in very

151 large numbers. Only three studies report observations of a single X. laevis (Lobos \& Garín 2002; Eggert \& 
152 Fouquet 2006; Vanschoenwinkel et al. 2008). Several anecdotes refer to spectacular mass overland

153 movements of $X$. laevis in native and invasive populations (reported by Channing 2001; Crayon 2005;

154 Hewitt \& Power 1913; Lobos \& Jaksic 2005). These examples all have the drying of an impoundment in

155 common, where animals appear motivated to move by reduction in water level but notably do not wait

156 until there is no water, instead leaving when levels are very low. There is a single account which

157 suggests that such mass movements do not occur only as impoundments dry: Wager (1986) comments

158 on large numbers of animals moving overland after heavy rains. The best documented account of mass

159 overland movement comes from the observations of Gabriel Lobos who reported on movement in an

160 invasive population of $X$. laevis in Chile. He noted that water levels had dropped to $5-15 \mathrm{~cm}$ (from

161 several metres deep when the impoundment was full: Lobos \& Jaksic 2005). The animals that moved

162 were in good condition, with no apparent sex bias (although no juveniles were seen moving) and

163 estimated to number several thousand. A previous estimate of population for the same impoundment

164 suggested that two years earlier numbers may have been as high as 20000 (Lobos \& Measey 2002).

165 Mass movements when water-bodies dry are also reported in South Africa, resulting in large amounts of

166 associated road-kill (N. Passmore pers. comm.). One noteworthy observation is that when moving en

167 masse, the animals form an unbroken chain (Lobos \& Jaksic 2005; Weisenberger 2011). This might

168 reflect the lead animals being stimulated by olfaction (Savage 1961), while those following cannot see

169 their leaders (see Elepfandt 1996) and may not obtain olfactory cues, therefore trying to remain in

170 physical contact with them. Perhaps unsurprisingly, anecdotes of smaller numbers of Xenopus moving

171 have also been recorded when impoundments are drying (e.g. Loveridge 1976).

172

173 Records of mass movements suggest that entire populations move (Channing 2001; Crayon 2005; Hewitt

174 \& Power 1913; Lobos \& Jaksic 2005), but no reports have specifically tested this idea. In the cases where

175 impoundments have dried and when burrowing into the substrate is not an option, it may be safe to

176 assume that all individuals were forced to make overland movements. The coordinated onset of mass

177 movement from drying puddles in X. laevis (Lobos \& Jaksic 2005) receives support from other

178 synchronised behaviours such as air breathing (Baird 1983). The only study that estimated the frequency

179 of individuals moving overland suggests a surprisingly high proportion of the population. Measey \&

180 Tinsley (1998) report movements between capture sites (which necessitated overland movements) for

$18121 \%$ of individuals captured more than once in and around the Afon Alun, South Wales. At the other

182 locality (Dunraven) this was as high as $36 \%$ although it is not clear whether animals had actually moved

183 overland due to the existence of subterranean aquifers. Some authors mention movements between 
184 flowing and still water-bodies (McCoid \& Fritts 1980; Measey \& Tinsley 1998). Measey (1997) reports on

185 recaptures from invasive Welsh populations and states that recaptures in ponds very close to a river were most common when the river was not flowing (see also Measey \& Tinsley 1998; Tinsley et al. 2015). This appears to suggest that these individuals were using permanent ponds mostly when the river dried. Interestingly, subsequent studies in the same area suggest that these movements decreased over time as the population waned (Tinsley et al. 2015). This may indicate that movements are driven, at least in part, by the existence of populations with high densities (see also McCoid \& Fritts 1980). Measey (1997) further notes that movements from river to ponds "...would have to be overland, and in the cases of FP and TFP [abbreviations of pond names], obstacles including vertical walls (up to $0.5 \mathrm{~m}$ ) and dense hedgerows would have had to be traversed. Some of the animals caught were noted to have heavy scarring of dorsum and ventrum, consistent with movement over such terrain." This suggests that $X$. laevis are able to overcome modest obstacles in their path, in order to gain access to water-bodies. This concurs with observations in South Africa where walls and thick vegetation are regularly traversed (JM pers. obs., also see Schramm 1987). Similar observations have been made in other invasive populations where it was inferred that individuals had to move up steep walls and slippery slopes (R. Rebelo pers. comm.). It would be of interest to determine whether these distributional inferences are accurate before considering building barriers to prevent dispersal in invasive populations of $X$. laevis. For example, a $0.7 \mathrm{~m}$ high concrete wall failed to keep X. laevis out of a X. gilli breeding pond (Fogell et al. 2013; Picker \& de Villiers 1989).

\section{Distances moved overland by X. laevis}

Reports of distances moved overland by $X$. laevis in the literature vary from $40 \mathrm{~m}$ to $2 \mathrm{~km}$ (Table 1 ) and are comparable to distances travelled by other terrestrial amphibians (Smith \& Green 2005). The distribution of distances reported appears to suggest that shorter distances are more unusual, very unlike a dispersal kernel for most anurans (see for example Smith \& Green 2005). However, a closer examination of the data sources reveals that most are anecdotal and are thus more likely to record longer movements, while empirical studies record both long and short distances. Distances of distributional displacements are in general accordance with those measured by empirical studies (Table 1), but both suffer from a lack of information about conditions during which movements occur. For example, McCoid \& Fritts (1980) refer to sheet flooding facilitating the movement of juvenile $X$. laevis $800 \mathrm{~m}$ in San Diego County, USA. But Lobos \& Jaksic (2005) specified that movements of nearly $200 \mathrm{~m}$ were made across dry ground near San Diego, Chile. Thus, it is hard to treat distances reported in the 
216 literature comparatively, as they may relate to quite different scenarios, with respective distances

217 estimated in different ways. Measey \& Tinsley (1998) and Measey (1997) who report the longest

218 distances for overland movement of $X$. laevis of up to $2 \mathrm{~km}$, provide straight line distances between

219 capture sites, whereas distances actually travelled could have been much longer. However, this total

220 distance could have included use of a river, making the maximum distance moved overland not $2 \mathrm{~km}$ but

221 approximately $450 \mathrm{~m}$, if dispersal events occurred through the flowing river. Most distances reported in

222 the literature do not provide any indication of how they were estimated. Despite these issues, it is clear

223 that $X$. laevis is able to move substantial distances overland There is very clear evidence from one study

224 that $X$. laevis are capable of moving at least $0.45 \mathrm{~km}$ overland (Measey \& Tinsley 1998), and more

225 ambiguous evidence from two others indicating distances up to $1 \mathrm{~km}$ are possible (McCoid \& Fritts 1980;

226 Wager 1986).

227

228

Is overland movement nocturnal, seasonal or weather-dependent in Xenopus laevis?

229

When weather is mentioned, nine out of 12 authors note that overland movements occur during or shortly after rain (Channing 2001; Du Plessis 1966; Eggert \& Fouquet 2005; Fouquet \& Measey 2006; Hey 1949; Loveridge 1976; McCoid \& Fritts 1980; Picker 1985; Wager 1986). But movement does not appear to be confined to wet periods or during rain-showers as three studies specified that conditions were dry for mass and single overland movements (Hewitt \& Power 1913; Lobos \& Garín 2002; Lobos \& Jaksic 2005). In addition, I have observed a single $X$. laevis moving overland in the middle of austral summer without any apparent motivation from rainfall or drying habitats (JM pers. obs. 19h00, 28 January 2016, at Jonkershoek). Of the six papers that have specified the time of observed overland movement, five instances took place at night (Crayon 2005; Eggert \& Fouquet 2005; Lobos \& Garín 2002) or during the evening (Hewitt \& Power 1913; Lobos \& Jaksic 2005). Conversely, Loveridge (1976) recorded all overland movements of $X$. laevis early in the morning. That $X$. laevis would not move overland during the middle of the day (or at least would not start a movement during the day) does not sound unreasonable for a species which is prone to desiccation away from water. The available literature thus suggests that overland movements may peak during wet periods, but are by no means confined to rain or wet seasons.

Does $\underline{X \text {. laevis migrate? }}$

Observations recorded in the literature suggest that $X$. laevis move into ponds at the onset of rains, not only from areas that might have dried up, but also as normal/regular movement between ponds (Hey 
248 1949; Picker 1985). Clearly, if animals are aestivating out of water, such movements do not need a great 249 deal of explanation, but Hey (1949) and Picker (1985 - although it is not clear whether he refers to $X$. 250 laevis, X. gilli, or both) appear to describe the movement of animals from one pool to another. Hey

251 (1949) specifically interprets these movements as a migration to breed in temporary waters, and this is 252 repeated in correspondence reported by Mahrdt \& Knefler (1973). This record is of interest as Hey 253 extends his observation to include "defined migration routes" for mass movements that occur at night 254 in damp or cold weather. In addition, Hey notes that these routes result in mass mortalities when 255 interrupted (the example given is the construction of a new barn; Mahrdt \& Knefler 1973), a similar 256 observation having been made by Loveridge (1953).

Migration from permanent to temporary water-bodies for spawning would allow the spatial separation of adults from larvae which might otherwise be cannibalised (e.g. Measey 1998a; Measey et al. 2015; Schoonbee et al. 1992) as temporary waters are likely to have reduced densities of occupants. Similarly, temporary waters are likely to be high in nutrients, sometimes experiencing algal blooms and having reduced predator pressure, making them ideal habitats for developing larvae. Such observations and distributional inferences are available from other species (Rödel 2000; Thurston 1967), but for X. laevis, Du Plessis (1966) noted that ponds that were fertilised attracted frogs to move into them before any algae had time to grow. In accordance with many observations, the stimulus to move into temporary waters comes with the initial rains that fill them, and this is often combined with immediate egg laying (e.g. Balinsky 1969). A movement into a temporary water-body suggests a reciprocal movement upon drying conditions (see above), except that in many anecdotes it is not clear whether individuals have moved from other (presumably permanent) water-bodies, or simply aestivated in the dry substrate (Balinsky et al. 1967).

Hewitt \& Power (1913) recount an anecdote indicating that $X$. laevis were aestivating in the mud of a pond, and that when this mud was moved to a new location the frogs continued to aestivate, only reemerging from this new location following rains. Such particular observations have also been made elsewhere (A. Channing pers. comm.). This suggests that animals do burrow into the mud of some temporary waterbodies, but this does not seem to be consistent, as Hewitt \& Power (1913) also note. It

277 is worth noting that Crayon (2005) suggested that Tinsley \& McCoid (1996) reported migration of "...0.2

$278 \mathrm{~km}$ in late spring to a spawning site", but the idea that this was a migration to a spawning site was an embellishment by Crayon. Fuller accounts of the same movement (Measey 1997; Measey \& Tinsley 
280

281

282

283

284

285

286

287

288

289

290

291

292

293

294

295

296

297

298

299

300

301

302

303

304

305

306

307

308

309

310

311

1998), simply refer to a movement from a permanent pond to a temporary one within 48 hours. Other data suggesting migration in the Welsh studies imply that animals moved from the seasonal river into permanent ponds (see above), although this could be interpreted as movement due to drying of habitat. Of all citations given by Crayon (2005) suggesting breeding migrations, only Hey (1949) and Hey's comments in Mahrdt \& Knefler (1973) actually state this. Although there is no reason to dismiss Hey's statements, since he clearly was very familiar with the biology of this species after raising animals at Jonkershoek for export (see van Sittert \& Measey 2016), he offered no evidence of migration, be it anecdotal or empirical. Thus the literature provides a clear hypothesis that $X$. laevis may migrate to spawn, as many other anurans are known to (e.g. Lizana et al. 1994), but it seems likely that this behaviour would be context dependent. In the majority of its indigenous and invasive ranges, waterbodies inhabited by $X$. laevis are anthropogenically created impoundments. Testing a hypothesis on migration in $X$. laevis would require a set of relevant, natural water-bodies.

\section{Overland movement in other Xenopus species}

This review of the literature presents sufficient anecdotal and distributional data of other Xenopus species suggesting that many of these also move overland (Table 1). There are data that indicate movement during dry periods in $X$. borealis, which suggests that mass movements also occur in other species (Weisenberger 2011). Perhaps unsurprisingly, there are other anecdotal observations of mass movements for X. borealis (Loveridge 1953), as well as X. muelleri (Loveridge 1953; Thurston 1967). Movements overland outside of rainy periods also exist for $X$. tropicalis (Rödel 2000 and references therein) and suggest that, like $X$. laevis, other Xenopus species move throughout the year irrespective of rains. To date, there is no reason to suspect that $X$. laevis moves any further overland than any of its congeners (see Table 1), despite its larger size. However, there are no suggestions that any congeners migrate to breed, which is perhaps not surprising, given that there is only a single suggestion of this happening for X. laevis (Hey 1949). Thus, none of the movement data existing for other Xenopus species appear to contradict the findings here for $X$. laevis, prompting the question of whether any Xenopus species might be expected to be substantially different in their overland movement patterns? One species, $X$. longipes, stands out as, within the genus, it appears to be an example of a taxon which exhibits extreme adaptation to an aquatic lifestyle. Moreover, it is found in a single, hydrologically closed locality, namely Lake Oku, and no specimens have ever been found outside this lake, despite a recent increase in research interest in this species. As residents of a volcanic lake in the Cameroon highlands, it seems unlikely that this species would ever have experienced a drying habitat that might 
312 have prompted overland dispersal. Similarly, a lack of food and conditions prompting mass mortality

313 events did not involve individuals leaving Lake Oku (Blackburn et al. 2010; Loumont \& Kobel 1991).

314 Use of Literature

315 Analysis of the use of literature allows an overview into the importance of this topic. The majority of

316 studies (26 papers on X. laevis and 2 on other Xenopus species) which were found in the literature

317 search did not have data on Xenopus overland movement (circles on right in Figure 2). Those with

318 original observations were mostly anecdotal in nature (13 papers on X. laevis and 6 on other Xenopus

319 species are shown as squares on the left in Figure 2), relaying information on instances where Xenopus

320 have been observed moving overland. There was a clear trend over time for observations to move from

321 anecdotes to distributional or mark-recapture data (4 triangles and 4 stars, respectively), with interest in

322 the topic clearly increasing as $60 \%$ of publications were published in the last 20 years (1995 to 2015) of

323 the 102-year period. The majority of citations referred to publications with observations (curves above a

324 direct connecting line between columns) or to reviews. However, there were several instances where

325 curves below the line suggest that authors were citing publications without any data or observations. It

326 is hoped that this review will help alleviate any past discrepancies in this respect. The network also

327 showed that many of the citations refer to work that was conducted on invasive populations; to date, no

328 empirical data exists on indigenous $X$. laevis moving overland, although both anecdotes and

329 distributional inferences have been made. There is a clear need for empirical work in general, but in

330 particular to fill the deficit identified here regarding indigenous populations of $X$. laevis. Limitations in

331 the literature search were partially alleviated by adding expert knowledge of the literature, as well as

332 using citations to publications from all articles identified. The existence of uncited literature, however,

333 suggests that searches may not have been exhaustive and that other information on overland

334 movement, particularly in other Xenopus species may shed further insight into this behaviour. There is

335 clearly potential for new empirical studies on movements of Xenopus species within their native range.

\section{Conclusion}

337 A review of the literature has shown that overland movements of Xenopus laevis have been found in 338 both its native and invasive ranges. Although no empirical data exists for their native range, there is 339 nothing to suggest that overland movements will be found to be less substantial or frequent than in 340 their invasive range. Given the paucity of empirical studies, distances moved appear to conform to those 341 typical for other anurans, with large numbers of animals moving short distances and some individuals 
342

moving up to $2 \mathrm{~km}$ (direct distance). The literature does not appear to agree on whether overland movements are seasonal, although the majority of studies suggest that movements are more frequent when conditions are wet and they tend not to happen during the middle of the day. Lastly, although suggested, there is currently no evidence in the literature to support the notion that overland movements are migrations to and from water-bodies for individuals to spawn. In addition to providing an overview on overland movements in $X$. laevis, this review also suggests that movement and breeding patterns for $X$. laevis may be similar to other members of the genus Xenopus. Although this review only mentions overland movement in six of 29 currently described species (Frost 2016), lack of reports for the other species probably relates to a lack of research.

\section{Acknowledgements}

I would like to thank those people who helped me obtain literature: Marié Theron, Alan Channing, Ed Stanley and Dennis Rödder. Thanks also to Brent Abrahams for help with the Gephi analysis. Lastly, I thank members of the MeaseyLab (especially André de Villiers and Ana Nunes), Thalassa Matthews, Donald Kramer and the INVAXEN group for fruitful discussions and comments on an earlier version of this manuscript.

\section{Literature Cited}

Baird TA. 1983. Influence of social and predatory stimuli on the air-breathing behavior of the African clawed frog, Xenopus laevis. Copeia 1983:411-420. 10.2307/1444384

Balinsky BI. 1969. The reproductive ecology of amphibians of the Transvaal Highveld. Zoologica Africana 4:37-93.

Balinsky JB, Choritz EL, Coe GL, and van der Schans GS. 1967. Amino acid metabolism and urea synthesis in naturally aestivating Xenopus laevis. Comp Biochem Physiol 22:59-68.

Blackburn DC, Evans BJ, Pessier AP, and Vredenburg VT. 2010. An enigmatic mortality event in the only population of the Critically Endangered Cameroonian frog Xenopus longipes. African Journal of Herpetology 59:111-122. Pii 92487841310.1080/04416651.2010.495674

Carreño CA, and Nishikawa KC. 2010. Aquatic feeding in pipid frogs: the use of suction for prey capture. Journal of Experimental Biology 213:2001-2008.

Channing A. 2001. Amphibians of central and southern Africa: Comstock Pub. Associates.

Crayon JJ. 2005. Species account: Xenopus laevis. In: Lannoo MJ, ed. Amphibian Declines: The Conservation Status of United States Species. Berkeley: University of California Press, 522-525.

Du Plessis S. 1966. Stimulation of spawning in Xenopus laevis by fowl manure. Nature 211:1092.

Eggert C, and Fouquet A. 2005. A preliminary biotelemetric study of a feral invasive Xenopus laevis population in France. Alytes 23:3-4.

Elepfandt A. 1996. Underwater acoustics and hearing in the clawed frog, Xenopus. In: Tinsley RC, and Kobel HR, eds. The Biology of Xenopus. Oxford: Oxford University Press. 
379

380

381

382

383

384

385

386

387

388

389

390

391

392

393

394

395

396

397

398

399

400

401

402

403

404

405

406

407

408

409

410

411

412

413

414

415

416

417

418

419

420

421

422

423

424

425

426

Elepfandt A, Eistetter I, Fleig A, Gunther E, Hainich M, Hepperle S, and Traub B. 2000. Hearing threshold and frequency discrimination in the purely aquatic frog Xenopus laevis (Pipidae): Measurement by means of conditioning. Journal of Experimental Biology 203:3621-3629.

Emerson SB. 1979. The ilio-sacral articulation in frogs: form and function. Biological Journal of the Linnean Society 11:153-168.

Evans BJ, Carter TF, Greenbaum E, Gvoždík V, Kelley DB, McLaughlin PJ, Pauwels OS, Portik DM, Stanley EL, and Tinsley RC. 2015. Genetics, morphology, advertisement calls, and historical records distinguish six new polyploid species of African clawed frog (Xenopus, Pipidae) from West and Central Africa. PloS one 10:e0142823. 10.1371/journal.pone.0142823

Fogell DJ, Tolley KA, and Measey GJ. 2013. Mind the gaps: investigating the cause of the current range disjunction in the Cape Platanna, Xenopus gilli (Anura: Pipidae). PeerJ 1:e166. DOI 10.7717/peerj.166

Fouquet A, and Measey GJ. 2006. Plotting the course of an African clawed frog invasion in Western France. Animal Biology 56:95-102. Doi 10.1163/157075606775904722

Freitag J, Krieger J, Strotmann J, and Breer H. 1995. Two Classes of olfactory receptors in Xenopus laevis. Neuron 15:1383-1392.

Frost DR. 2016. Amphibian Species of the World: an Online Reference. Version 6.0 New York, USA.: American Museum of Natural History.

Furman BLS, Bewick AJ, Harrison TL, Greenbaum E, Gvoždík V, Kusamba C, and Evans BJ. 2015. PanAfrican phylogeography of a model organism, the African clawed frog 'Xenopus laevis'. Molecular Ecology 24:909-925. 10.1111/mec.13076

Gans C, and Parsons TS. 1966. On the origin of the jumping mechanism in frogs. Evolution:92-99.

Hewitt J, and Power JH. 1913. A list of S. African Lacertilia, Ophidia and Batrachia in the McGregor Museum, Kimberley, with field notes on various species. Transactions of the Royal Society South Africa 3:147-176.

Hey D. 1949. A report on the culture of the South African clawed frog Xenopus laevis (Daudin) at the Jonkershoek inland fish hatchery. Transactions of the Royal Society of South Africa 32:45-54.

Ihlow F, Courant J, Secondi J, Herrel A, Rebelo R, Measey GJ, Lillo F, Villiers FAd, Vogt S, Buchere Cd, Backeljau T, and Rödder D. 2016. Impacts of climate change on the global invasion potential of the African clawed frog Xenopus laevis. PloS one 11:e0154869.

Katbamna B, Brown JA, Collard M, and Ide CF. 2006. Auditory brainstem responses to airborne sounds in the aquatic frog Xenopus laevis: correlation with middle ear characteristics. Journal of Comparative Physiology A 192:381-387. 10.1007/s00359-005-0076-3

Kobel HR, Loumont C, and Tinsley RC. 1996. The extant species. In: Tinsley RC, and Kobel HR, eds. The Biology of Xenopus. Oxford: Oxford University Press, 9-34.

Lizana M, Márquez R, and Martín-Sánchez R. 1994. Reproductive biology of Pelobates cultripes (Anura: Pelobatidae) in central Spain. Journal of Herpetology 28:19-27. Doi 10.2307/1564675

Lobos G, and Garín C. 2002. Xenopus laevis (African clawed frog). Herpetological Review 33:132.

Lobos G, and Jaksic FM. 2005. The ongoing invasion of African clawed frogs (Xenopus laevis) in Chile: causes of concern. Biodiversity and Conservation 14:429-439. 10.1007/s10531-004-6403-0

Lobos G, and Measey GJ. 2002. Invasive populations of Xenopus laevis (Daudin) in Chile. Herpetological Journal 12:163-168.

Loumont C, and Kobel HR. 1991. Xenopus longipes sp. nov., a new polyploid pidid from western Cameroon. Rev Suisse Zool 98:731-738.

Loveridge A. 1953. Zoological results of a fifth expedition to East Africa. IV Amphibians from Nyasaland and Tete. Bulletin of the Museum of Comparative Zoology at Harvard University 110:325-406.

Loveridge J. 1976. Strategies of water conservation in southern African frogs. Zoologica Africana 11:319333. 
427

428

429

430

431

432

433

434

435

436

437

438

439

440

441

442

443

444

445

446

447

448

449

450

451

452

453

454

455

456

457

458

459

460

461

462

463

464

465

466

467

468

469

470

471

472

473

Mahrdt CR, and Knefler FT. 1973. The clawed frog-again. Environment Southwest 450:1-3.

Mason M, Wang M, and Narins P. 2009. Structure and function of the middle ear apparatus of the aquatic frog, Xenopus laevis. Proceedings of the Institute of Acoustics Institute of Acoustics (Great Britain) 31:13.

McCoid MJ, and Fritts TH. 1980. Notes on the diet of a feral population of Xenopus laevis (Pipidae) in California. Copeia 1980:272-275.

Measey GJ, Rödder D, Green S, Kobayashi R, Lillo F, Lobos G, Rebelo R, and Thirion J-M. 2012. Ongoing invasions of the African clawed frog, Xenopus laevis: a global review. Biological Invasions 14:2255-2270. 10.1007/s10530-012-0227-8

Measey GJ. 1997. The ecology of Xenopus PhD. Bristol University.

Measey GJ. 1998a. Diet of feral Xenopus laevis (Daudin) in South Wales, UK. Journal of Zoology 246:287298.

Measey GJ. 1998b. Terrestrial prey capture in Xenopus laevis. Copeia 1998:787-791. Doi $10.2307 / 1447816$

Measey GJ, and Tinsley RC. 1998. Feral Xenopus laevis in South Wales. Herpetological Journal 8:23-27.

Measey GJ, Vimercati G, De Villiers FA, Mokhatla MM, Davies SJ, Edwards S, and Altwegg R. 2015. Frog eat frog: exploring variables influencing anurophagy. PeerJ 3:e1204. 10.7717/peerj.1204

Measey J. in press. Where do African clawed frogs come from? An analysis of trade in live Xenopus laevis imported into the USA. Salamandra.

Moher D, Liberati A, Tetzlaff J, and Altman DG. 2009. Preferred reporting items for systematic reviews and meta-analyses: The PRISMA statement. Annals of Internal Medicine 151:264-269. 10.7326/0003-4819-151-4-200908180-00135

Picker MD. 1985. Hybridization and habitat selection in Xenopus gilli and Xenopus laevis in the southwestern Cape Province. Copeia:574-580.

Picker MD, and de Villiers AL. 1989. The distribution and conservation status of Xenopus gilli (Anura, Pipidae). Biological Conservation 49:169-183.

Poynton JC. 1964. The Amphibia of sourthern Africa. Annals of the Natal Museum 17:1-334.

Rödel M-O. 2000. Herpetofauna of West Africa Vol. I Amphibians of the West African Savanna. Frankfurt am Main, Germany: Edition Chimaira.

Savage RM. 1961. The Ecology and Life History of the Common Frog (Rana temporaria temporaria). London: Sir Isaac Pitman \& Sons, Ltd.

Schoonbee HJ, Prinsloo JF, and Nxweni JG. 1992. Observations on the feeding habits of larvae, juvenile, and adult stages of the African clawed frog, Xenopus laevis, in impoundments in Transkei. Water SA 18:227-236.

Schramm M. 1987. Control of Xenopus laevis (Amphibia: Pipidae) in fish ponds with observations on its threat to fish fry and fingerlings. Water SA (Pretoria) 13:53-56.

Sinsch U. 2006. Orientation and navigation in Amphibia. Marine and Freshwater Behaviour and Physiology 39:65-71. 10.1080/10236240600562794

Smith MA, and Green DM. 2005. Dispersal and the metapopulation paradigm in amphibian ecology and conservation: are all amphibian populations metapopulations? Ecography 28:110-128.

Thurston JP. 1967. The morphology and life-cycle of Cephalochlamys namaquensis (Cohn, 1906)(Cestoda: Pseudophyllidea) from Xenopus muelleri and X. laevis. Parasitology 57:187-200.

Tinsley RC, and McCoid MJ. 1996. Feral populations of Xenopus outside Africa. In: Tinsley RC, and Kobel HR, eds. The Biology of Xenopus. Oxford: Oxford University Press, 81-94.

Tinsley RC, Stott LC, Viney ME, Mable BK, and Tinsley MC. 2015. Extinction of an introduced warmclimate alien species, Xenopus laevis, by extreme weather events. Biological Invasions 17:31833195. 10.1007/s10530-015-0944-x 
474 Travis J. 2006. Is it what we know or who we know? Choice of organism and robustness of inference in ecology and evolutionary biology. American Naturalist 167:303. Doi 10.1086/501507

Trueb L. 1996. Historical constraints and morphological novelties in the evolution of the skeletal system of pipid frogs (Anura: Pipidae) In: Tinsley RC, and Kobel HR, eds. The Biology of Xenopus. Oxford: Oxford University Press, 349-377.

van Sittert L, and Measey GJ. 2016. Historical perspectives on global exports and research of African clawed frogs (Xenopus laevis). Transactions of the Royal Society of South Africa 71:157-166. of different dispersal vectors for small aquatic invertebrates in a rock pool metacommunity. Ecography 31:567-577. 10.1111/j.0906-7590.2008.05442.x

485 Wager VA. 1986. Frogs of South Africa their fascinating life stories. Johannesburg: Delta Books.

486 Weisenberger ME. 2011. Xenopus borealis: terrestrial activity. African Herp News 53:44-45. 


\section{Table $\mathbf{1}$ (on next page)}

Table showing distances moved by Xenopus species recorded in the literature

Distances moved by Xenopus species recorded in the literature. 
1 Table 1: Overland distances moved by Xenopus species recorded in the literature.

\begin{tabular}{|c|c|c|c|c|c|}
\hline Reference & Species & $\begin{array}{l}\text { Number of } \\
\text { individuals }\end{array}$ & Distance reported $(\mathrm{km})$ & Data type & Population \\
\hline \multirow[t]{2}{*}{ Loveridge (1953) } & X. borealis & unspecified & 0.45 & Anecdotal & indigenous \\
\hline & X. muelleri & $>14$ & 0.9 & Anecdotal & indigenous \\
\hline Inger (1968) & X. muelleri & 1 & 0.02 & Anecdotal & indigenous \\
\hline McCoid \& Fritts (1980) & $X$. laevis & unspecified & 0.8 & Anecdotal & invasive \\
\hline Picker (1985) & $X$. gilli & 11 & 0.9 & Empirical & indigenous \\
\hline Wager (1986) & X. laevis & thousands & 1.0 & Anecdotal & indigenous \\
\hline Measey \& Tinsley (1998)* & X. laevis & $55(21 \%$ of & 0.2 (within $48 \mathrm{hrs}$ ) & Empirical & invasive \\
\hline \multirow[t]{2}{*}{ (Measey 1997)* } & & recaptures) & $0.75,1.5 \& 2.0$ (direct & & \\
\hline & & & distance) & & \\
\hline Lobos \& Garín (2002) & X. laevis & 1 & 0.04 & Anecdotal & invasive \\
\hline Lobos \& Jaksic (2005) & X. laevis & hundreds & 0.1 to 0.18 & Anecdotal & invasive \\
\hline Eggert \& Fouquet (2005) & X. laevis & 1 & 0.08 & Empirical & invasive \\
\hline Faraone et al. (2008) & $X$. laevis & unspecified & 0.48 & Inferred & invasive \\
\hline
\end{tabular}

*These sources report the same data. 


\section{Figure 1 (on next page)}

Prisma flow-diagram (see Moher et al. 2009) for literature included in this study.

Flow-diagram for literature on Xenopus overland movement included in this study. 
PRISMA 2009 Flow Diagram

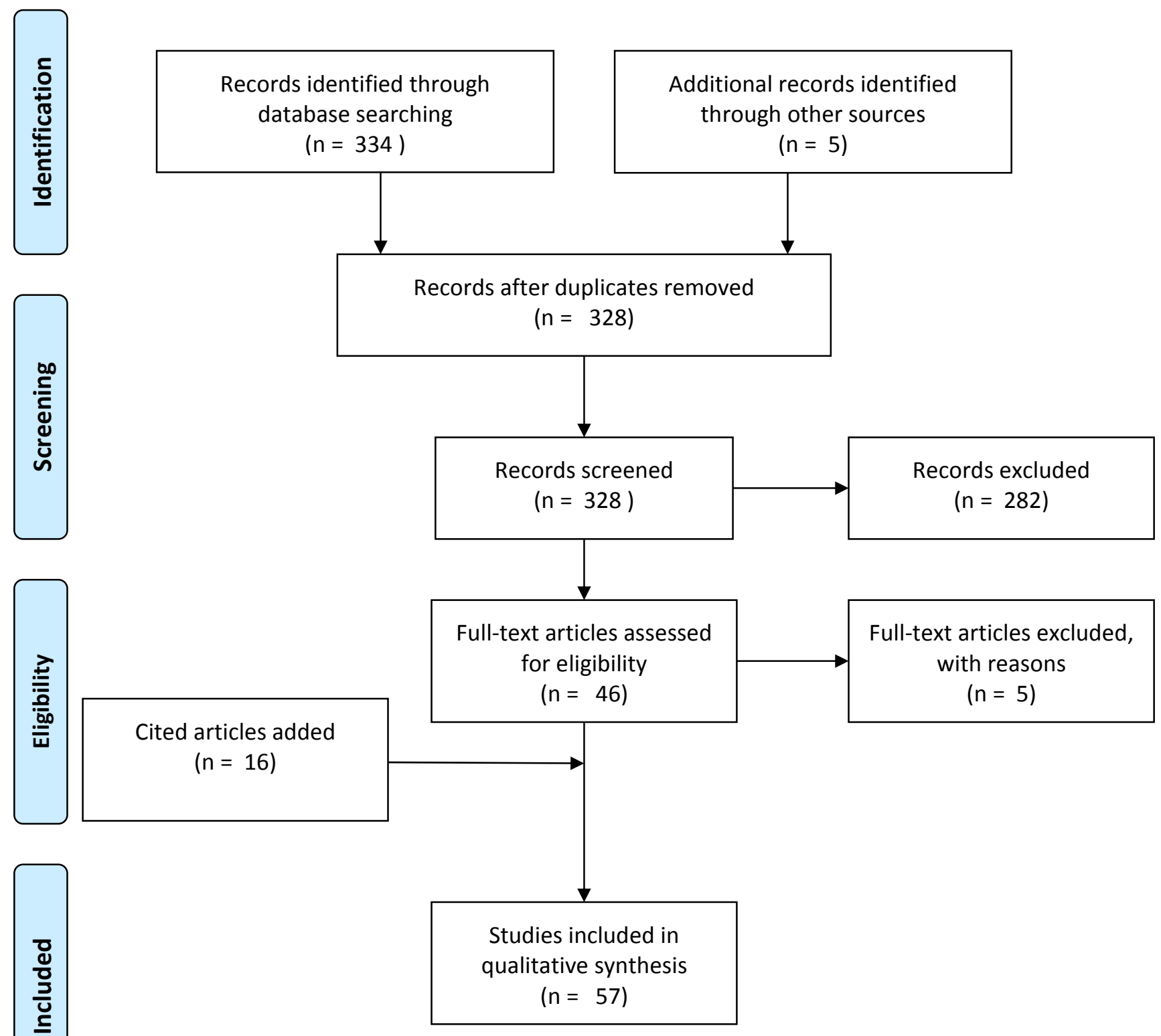

From: Moher D, Liberati A, Tetzlaff J, Altman DG, The PRISMA Group (2009). Preferred Reporting Items for Systematic Reviews and MetaAnalyses: The PRISMA Statement. PLoS Med 6(7): e1000097. doi:10.1371/journal.pmed1000097 


\section{Figure 2 (on next page)}

Network visualisation for Xenopus overland movement literature

A network visualisation of literature mentioning overland movement in Xenopus using Gephi. Literature is sorted into that with data (left): anecdotal (squares), inferred (triangles), and empirical (stars); literature reviews (middle: hexagons); and literature which does not have original data on overland movement in Xenopus (circles: right). Different species of Xenopus are denoted by different colours, and indigenous $X$. laevis (blue filled symbol) are differentiated from invasive populations (red filled blue symbol). Other species are coded as

other colours: $X$. muelleri (green), $X$. borealis (pink), X. gilli (yellow), X. fraseri (grey), X. clivii (purple) and $X$. tropicalis (cyan). Curves connecting nodes denote the direction of the citation: above the line (right to left) or below the line (left to right). Nodes which are not connected represent literature which does not cite and has not been cited in relation to Xenopus movement overland. For complete references to the citations, please refer to Supplementary Informtaion. 
Hewitt \& Power 1913

Hey 1949

Loveridge 1953

du Plesis 1966

Thurston 1967

Inger 1968

Mardht \& Knefler 1973

Loveridge 1976

McCoid \& Fritts 1980

Picker 1985

Wager 1986

Kazadi et al 1986

Schramm 1987

Yager 1996

Measey 1997

Measey \& Tinsley 1998

Channing 2001

Lobos \& Garin 2002

Lobos \& Jaksic 2005

Eggert \& Fouquet 2005

Fouquet \& Measey 2006

Vanschoenwinkel et al 2008

Faraone et al 2008

Weisenberger 2010

Lillo et al 2011

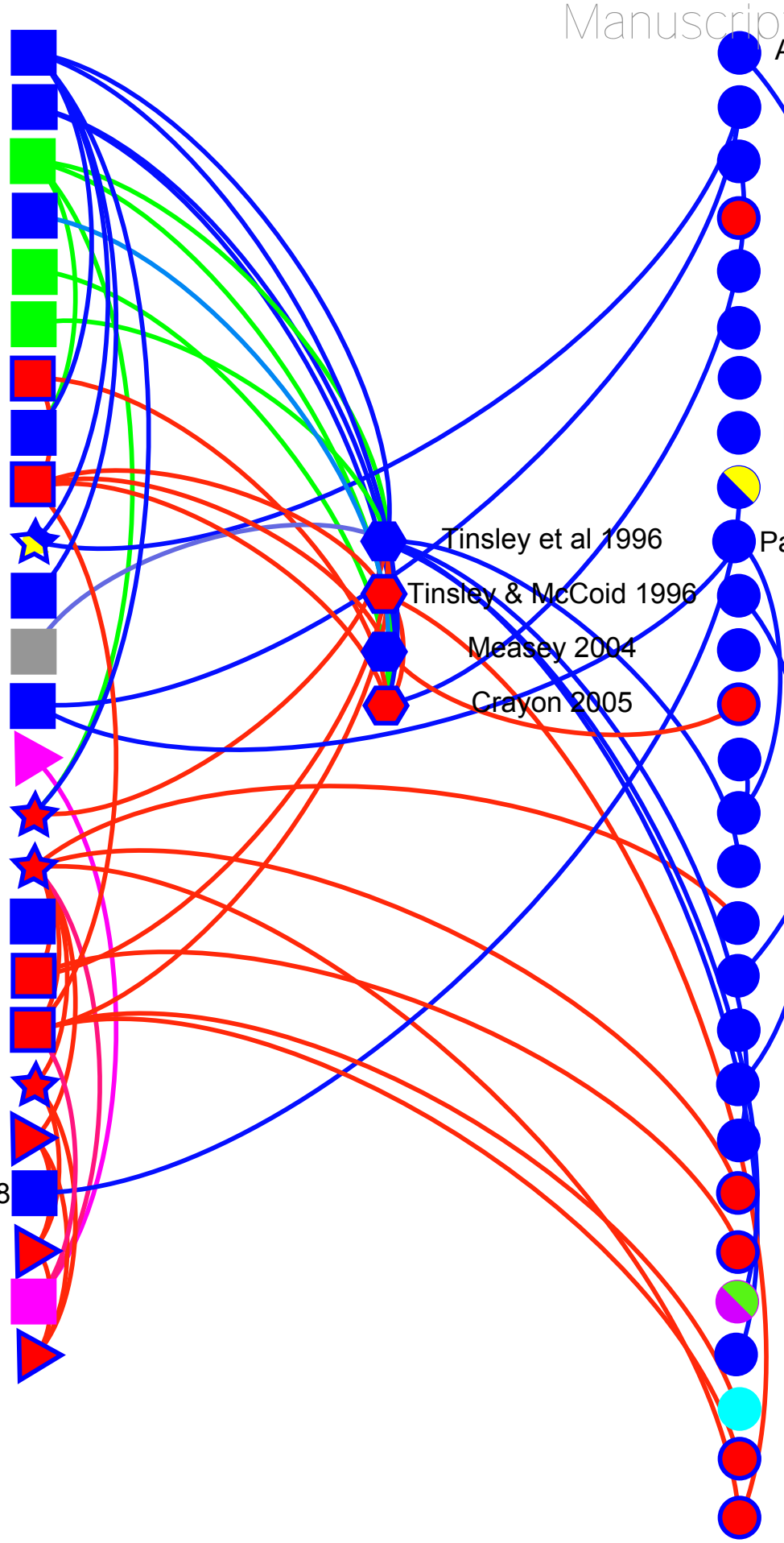

Alexander \& Bellerby 1938

Kalk 1960

Balinsky 1969

Mardht \& Knefler 1972

Tinsley \& Sweeting 1974

peuchar 1975

Tinsley \& Whitear 1980

Poyntop \& Broadley 1985

Simmonds 1985

Passmore \& Carruthers 1995

Tinsley \& Kobel 1996

Tinslef \& Jackson 1998

Measey 1998

Wilson et al 2000

Vilson et al 2002

Sullivan \& Spense 2003

Sinsch 2006

Storey \& Storey 2008

Malik \& Storey 2009

Malik \& Storey 2009b

Mason et al 2009

Rebelo et al 2010

Solis et al 2010

Evans et al 2011

Hillman et al 2011

Herrel et al 2012

Peralta et al 2014

Tinsley et al 2015 